\title{
Representation of the rain shadow effect in Patagonia us- ing an orographic-derived regional climate model
}

\author{
Adrien Damseaux \\ Department of Geography, University of Liège, Liège, Belgium. \\ Department of Geography, Simon Fraser University, Vancouver, Canada. \\ E-mail: adamseau@sfu.ca \\ Xavier Fettweis \\ Department of Geography, University of Liège, Liège, Belgium. \\ Marius Lambert \\ Department of Geography, University of Liège, Liège, Belgium. \\ Department of Geosciences, University of Oslo, Oslo, Norway \\ Yves Cornet \\ Department of Geography, University of Liège, Liège, Belgium.
}

Summary. This study focuses on Patagonia, where Foehn events observed in the lee of the Andes mountains are not yet well simulated by state-of-the-art climate models. It has been agreed that one source of this shortcoming is related to the poor relief representation in models. To resolve this need, a common method used is to enhance the spatial resolution of the model to retrieve a more complex surface elevation, at the expense of calculation time or surface area covered. This paper tackles the problem from a different angle by addressing the Digital Elevation Model (DEM) generalization, .i.e. the altitudes generalization from a high-resolution DEM to a coarser resolution grid model. Most current climate models use DEM generalization methods that smooth the relief, a key controlling factor in Foehn events modeling. The aim of this study is to compare three original methods of DEM generalization (percentile 90 (P90), envelope maximum (EM), and thalweg and crests (TC)) and to evaluate their impact on simulated precipitation and temperature fields on the eastern part of Patagonia, where warm and dry air masses are

This article has been accepted for publication and undergone full peer review but has not been through the copyediting, typesetting, pagination and proofreading process which may lead to differences between this version and the Version of Record. Please cite this article as doi: $10.1002 /$ joc. 6300 
expected. Thanks to MAR, a Regional Climate Model, we validate the models at 10 and $5 \mathrm{~km}$ resolutions against the Climate Research Unit and perform three sensitivity experiments involving a change in the DEM generalization. Our results show that (i) a finer spatial resolution can slightly improve the temperature biases, however, it cannot resolve the precipitation biases and (ii) a more appropriate use of DEM generalization induces a significant decrease in precipitation for the P90 and EM methods and an increase in mean temperature for all three methods in the study area. This study serves as a recommendation for a better use of DEM generalization in climate models performing in Patagonia, but also regions sharing the same orographic features as the Patagonian relief.

Foehn events, Digital Elevation Model, Orography, Spatial generalization, Spatial aggregation

\section{Introduction}

Due to its orographic, geographical and climatic situation, Patagonia is often mentioned as an excellent "laboratory" for studying Foehn events (Smith and Evans, 2007). Firstly, Patagonia lies between the subtropical high-pressure belt and the subpolar low-pressure areas that make it fully included in the area of prevailing westerly winds in the Southern Hemisphere. Secondly, the high and narrow Andes mountains, parallel to the oceans, stand as a topographic barrier intercepting perpendicular humid winds from the Pacific Ocean (Mazzoni and Vazquez, 2009). This second parameter is related to the term blocking effect. All factors are met to observe both highly pronounced upslope rains and Foehn events on the western and eastern side of the mountains, respectively, throughout the year (Paruelo et al., 1998; Seluchi et al., 2003; Berman et al., 2012; Viale and Garreaud, 2015). According to Garreaud et al. (2013), annual rainfall can exceed 5000$10,000 \mathrm{~mm} / \mathrm{yr}$ on the western slope of the Andes due to fast orographic rising air masses, whereas mean precipitation decreases to less than $250-300 \mathrm{~mm} / \mathrm{yr}$ a few tens of kilometres downstream and reaches 500-700 mm/yr close to the Atlantic coast. Mazzoni and Vazquez (2009) get similar results for the plain area. This distinctive aridity is generally related to the term "rain shadow effect" (Jacques-Coper et al., 2015). The west-eastward humidity and temperature gradients have huge consequences on the region, separating it 
into two climatic areas with their distinct biomes. The Andes mountains divide western wetland vegetation areas from eastern drier vegetation areas. This contrast is considered as "one of the most marked vegetation gradients in the world" (Mazzoni and Vazquez, 2009).

Because of its complex orographic features, the Foehn events in Patagonia have always been difficult to represent in climate models (Seluchi et al., 2003). At present time, few studies have provided high-resolution climate simulations at the regional level using Regional Climate Models (RCMs) over Patagonia. Solman et al. (2013) present a validation of seven RCMs using climate datasets at a $50 \mathrm{~km}$ resolution not exclusively in Patagonia but, for the whole South American continent during the 1990-2008 period. Over Patagonia, they note a systematic underestimation (over $1-2^{\circ} \mathrm{C}$ ) of the mean temperature and a large overestimation of precipitation. Another study by Lenaerts et al. (2014) uses a high-resolution $(5.5 \mathrm{~km}) \mathrm{RCM}$ to describe the present-day (1979-2012) climate of Patagonia, with a particular focus on the Surface Mass Balance (SMB) of Patagonian ice fields. Using a limited number of three stations, the validation shows model biases $\left(0\right.$ to $\left.-2^{\circ} \mathrm{C}\right)$ in all seasons and a marked overestimation of the precipitation in the eastern side of the Andes. In their study, the authors also underline the fact that the narrow mountain range is poorly resolved in low-resolution Global Climate Models (GCM) and atmospheric reanalysis products, like ERA-Interim (Dee et al., 2011). Consequently, the main advantage of a high-resolution model is the ability to reproduce a sharper surface elevation and the associated orographic precipitation, a feature that, they claim, would be absent in some state-of-the-art GCMs. Garreaud et al. (2013) use a $25 \mathrm{~km}$ resolution RCM to investigate the dependence of Patagonia's precipitation and near-surface air temperature on large-scale circulation anomalies during the 1978-2001 period. By comparing their results to 31 ground-based stations, the authors claim that the annual mean and seasonal amplitude of the surface air temperature are well simulated by the model. Nevertheless, their results show a significant underestimation of -0.5 to $-1^{\circ} \mathrm{C}$ during the last years of the simulations. Regarding the precipitation, they conclude that their RCM accurately simulates both interannual precipitation variability and annual precipitation. In another study, Garreaud et al. (2016) use the Weather 
Research and Forecasting (WRF) model and linear theory (LT) modeling to investigate precipitation distribution over a small part of Patagonia, the Nahuelbuta Mountains in northern Patagonia, during the 2011 winter period. They actually observe a consistent overestimation of the seasonal accumulation in terms of precipitation by a factor of 1.5 across their whole study area.

Following these studies, large uncertainties still remain in the modeling of Patagonian climate. There is a common underestimation of the annual mean temperature over the whole region and, in some studies, an overestimation of the annual precipitation. It should be noted that if the precipitation biases are mostly discussed in the mountains, questions about the absolute and relative precipitation in the eastern part were not fully addressed. In other words, much attention has been given to the representation of orographic-precipitation in high altitudes parts of Patagonia, whereas there is a lack of interest about the model ability to represent the rain shadow effect in Patagonia. Ultimately, all studies definitely underline the unambiguous correlation between a better relief representation in a high-resolution model and the associated orographic precipitation. This better representation would allow the blocking effect, key component of the Foehn events modeling (Elvidge and Renfrew, 2016), to be properly represented.

To resolve this need, a common method used in the literature is to improve the spatial resolution of the model to retrieve a finer and more complex surface elevation, at the expense of calculation time and/or surface area covered. This technique turned out to be successful in a large number of studies, in Patagonia (Lenaerts et al., 2014) but also in other regions over the world like in Greece (George et al., 2012), in Antarctica (Andrew et al., 2014), or in the USA (Wehner et al., 2010). This paper tackles the problem of modeling Foehn events in Patagonia from a different angle than by refining spatial resolution. Actually, we address the concept of Digital Elevation Model (DEM) generalization, i.e. the generalization of spatial data (e.g. surface altitude) thanks to different statistical and geometrical methods at a resolution coarser than the collected resolution provided by high-resolution models. It should be noted that some scholars use the term "DEM aggregation".

Climate models have to use a DEM generalization method to retrieve their surface 
elevation grid from a high-resolution orographic grid, usually derived from satellite or land-based observations (e.g. Amante and Eakings, 2009). However, based on our understanding, there is a lack of climate research tackling DEM generalization methods for the representation of the orography. Most current GCMs are using a similar approach to the mean box method, consisting of sampling DEM data through a box blur using the mean as a statistical parameter (Bindlish and Barros, 1996). The mean value of the high-resolution pixels is assigned to the homologous low-resolution pixel. This method, which can also be referred to Vieux (1993), preserves the total volume of orographic features at the expense of the amplitude of high spatial frequencies, i.e. it smoothes peaks and valleys. For instance, the Integrated Forecast System (IFS) model (from the European Centre For Medium Range Weather Forecasting - ECMWF) is using this mean box method detailed by ECMWF (2003). The relief generalization used in the Global Forecast System (GFS) model of the United States' National Weather Service (NWS), which can be found in Hong (1999), is similar to the standard deviation box method. This second method consists in adding a multiple of the local standard deviation of the high-resolution DEM to the mean orography (Bindlish and Barros, 1996). Although this method captures topographic peaks better than the corresponding mean orography, low elevation areas such as plains and valleys are not well resolved, and the total volume of orographic features is not maintained. Regarding the RCMs, there are many various and different models with incomplete DEM generalization method documentation. According to our understanding, most of them use a method close to the standard deviation box in combination with a specific filter. For example, RACMO 2.0 uses a Raymond filter which takes out the variance of the pixels altitude and reduces peaks amplitude (Lenderink and Lenderink, 2003). IPRC-RegCM uses a simple standard deviation method without filter (Wang et al., 2003).

In this study, we focus on the representation of the rain shadow effect in Patagonia, and particularly, on how DEM generalizations can impact climate model results. In answering this question, a reference run and three DEM generalization sensitivity experiments are performed with an orographic-derived version 3.9 of the RCM MAR (Fettweis et al., 2017) on Patagonia. First, the reference run evaluate the performance 
of the model against the Climate Research Unit (CRU) gridded climate dataset with two different MAR simulation at a given resolution of 10 and $5 \mathrm{~km}$. The objective is to demonstrate if an improvement of the spatial resolution can decrease the observed bias. The second step includes a series of sensitivity experiments. Each experiment includes a change in the DEM generalization method to assess the impacts of the surface elevation generalization on MAR outputs. We work on the hypothesis that a change in the orographic generalization method of a climate model can help us to better represent the rain shadow effect in Patagonia at low-resolution.

After this introduction in Section 1, Section 2 describes the study area, the model, the DEM generalization methods, and the data used in our study. After that, the results are presented in Section 3. Then, we conclude our research in Section 4 with some discussions and perspectives for further studies.

\section{Data and methods}

\subsection{Study area}

Our study focuses on the analysis of Foehn events in the Patagonian region. Consequently, the analyzed spatial domain, shown in Fig. 1, includes two areas with a 10 and a $5 \mathrm{~km}$ spatial resolution. They are wide enough to cover the whole southern tip of South America and part of the Pacific Ocean where the main winds are coming from.

As illustrated in Fig. 1, the areas cover a slightly different zone depending on their resolution. The aim is to preserve as much of the $10 \mathrm{~km}$ low-resolution domain while ensuring a rapid computing time, as a finer resolution by a factor 2 means a slower calculation time by a factor 8 .

\subsection{The Regional Climate Model MAR}

The Modèle Atmosphérique Régional (MAR), version 3.9, is used throughout our study. An RCM has been selected here since the spatial resolutions of GCMs are too coarse to accurately simulate Foehn events in Patagonia (Klink, 1995; Seluchi et al., 2003). The MAR model consists of a three-dimensional hydrostatic meso-scale primitive equation atmospheric model that can predict the evolution of a defined and restrained coupled 
land-atmosphere domain (Gallée and Schayes, 1994; Fettweis et al., 2005). The atmospheric part of MAR is fully described in Gallée and Schayes (1994) and Gallée et al. (1995). The RCM is coupled to the 1-D SISVAT (Soil Ice Snow Vegetation Atmosphere Transfer) module described in De Ridder and Gallée (1998). This involves three different sub-modules; (i) the soil and vegetation sub-module, (ii) the snow sub-module and (iii) the ice sub-module (Kittel et al., 2018). They simulate energy and mass fluxes between the surface and the atmosphere. The model was formerly developed to simulate katabatic winds (Gallée and Schayes, 1994) and its ability to simulate these winds has been extensively agreed (Gallée and Pettré, 1998; Mathiot et al., 2010; Barthélemy et al., 2012). Following these previous works, the MAR model seems a perfect candidate to simulate Foehn events which, although they are not similar, have some similarities with katabatic winds.

In this study, the MAR atmosphere and surface boundaries are forced every six hours by the ERA-Interim reanalysis developed by ECMWF at a $0.75^{\circ} \mathrm{x} 0.75^{\circ}$ spatial resolution. A complete description of ERA-Interim reanalysis is described in Dee et al. (2011).

The MAR preprocessing treatments are produced by an independent tool called NESTOR (NESTing Organization for the preparation of meteorological and surface fields in Regional models). The aim of this latter is to interpolate several geographical resources including a high-resolution DEM model and the climatic variables from ERA-Interim reanalysis to initialize the MAR domain. The generalization of the relief used by MAR occurs during this initialization. We, therefore, needed to go inside the source code of NESTOR to replace its former DEM generalization method by the ones we have developed.

\subsection{DEM generalization methods}

Previous scholars (Vieux, 1993; Wu et al., 2008; Le Coz et al., 2009) have highlighted that the suitability of generalization methods strongly depends on the orography of the study area. In other words, the effectiveness of the method varies according to the orographic specificities of the studied region. In our case, Patagonia shows both high peaks interspersed with deep valleys in a very narrow mountain range. The output surface elevation, 
therefore, needs to keep the amplitude of these high spatial frequencies. As previously stated, the mountain ridge is a crucial orographic feature to be represented because it induces the blocking effect of Foehn winds (Elvidge and Renfrew, 2016). Taking these factors into account, we have developed three original algorithms for DEM generalization to complement the former box mean method used as default in MAR: (i) the percentile 90 (P90) method, (ii) the envelope maximum (EM) method and (iii) the thalwegs and crests (TC) method. The high-resolution DEM used is the 1 arc-minute resolution global relief model of Earth's surface, ETOPO1. The complete documentation of this DEM can be found in Amante and Eakings (2009). Fig. 2 displays these 3 methods.

The P90 method consists of a box method, as explained earlier, using the percentile 90 as statistical parameter. Percentile 90 is chosen to keep a maximum of high altitudes for each box blur, to preserve the mountain range, with less over-smoothing of the valleys. The EM method goes further than the previous one by retaining to a large extent the high altitudes at the expense of the low altitudes. It exploits a rasterized TIN network of a relevant number of isolated summits over the area. A more detailed description of this method can be found in Appendix S1. Ultimately, the TC method consists in identifying a series of watersheds and thalwegs (line of the maximum area drained) over the study area using a series of hydrological procedures. This third method satisfies the need to preserve high altitude pixels while maintaining as many valleys as possible. As a result, both high spatial frequencies (low altitudes points with valleys and high altitudes point with crests) are maintained, increasing the relief amplitude. A more detailed description of this method can be found in Appendix S2.

A short analysis of the differences between the four generalization methods is available in Appendix S3.

One important precision is that the application of these methods is limited to the surface elevation model area representing the mountain range (Fig. 3). Outside this box zone, the mean method is used in all elevation surfaces. This choice was made to only compare pixels with the same altitude in the plain area, where the rain shadow effect is expected. We acknowledge that the threshold, i.e. the separation of the two regions representing the mountains and the plain, was chosen on a subjective basis and 
without any quantitative analysis. Further studies should look for a hybrid generalization method taking into account the altitudinal features of the region. Finally, a buffer zone of two pixels along the western and eastern sides of the plain-mountain border was created to allow a smoother transition between the two DEM generalization methods and, consequently, stability for the model.

\subsection{CRU database and model validation}

A large consensus of scholars (Garreaud et al., 2013; Lenaerts et al., 2014; Bianchi et al., 2016) instinctively suggests that, like many other sparsely populated areas, the Patagonian region holds a low spatial density meteorological network with short time-period record that do not properly describe climate variability and do not allow climate models validations. This limitation is increased by the fact that Patagonia is characterized by a complex spatial variability in precipitation and temperature. For that reason, our study uses observational gridded climate datasets as an alternative approach, to validate climate models. Previous studies have shown the benefit of this method to overcome the meteorological network limitation of Patagonia (Bianchi et al., 2016). Notwithstanding the knowledge of this limitation and the benefits of gridded climate datasets, most recent studies have preferred in-situ measurements at the detriment of a validation using observational gridded climate datasets. It should be noted that other scholars have pointed out that the quality of observational gridded climate datasets in complex relief is questionable (Solman et al., 2013), as the resolution of the gridded data set is too coarse to resolve the topography. Since this study focuses on the eastern flatter area of Patagonia, this warning should be limited though.

Among all the gridded climate datasets available, we have decided to carry out our model validation exclusively with the Climate Research Unit (CRU) database. The CRU TS v.4.01 database at a resolution of $0.5^{\circ} \times 0.5^{\circ}$ produced at the University of East Anglia is used (Harris et al., 2014). The variables used here are the mean temperature and the precipitation, key components of the climatic variables of Foehn events. 


\section{Results}

\subsection{Validation of MAR}

A first reference run performed by the MAR version 3.9 with two different spatial resolution (10 and $5 \mathrm{~km}$ ), using the former generalization method (the default mean method of $\mathrm{MAR}$ ), is evaluated against the CRU data set on the native $0.5^{\circ} \mathrm{x} 0.5^{\circ} \mathrm{CRU}$ grid (thanks to a simple bilinear interpolation) over the 2002-2016 period with four months of spin-up. The temporal resolution of all simulations made by MAR is 120 seconds. We perform a model validation in two different resolution to observe if a finer resolution produces results closer to observations.

\section{Temperature biases}

Fig. 4a shows a general annual mean temperature underestimation of -1 to $-3^{\circ} \mathrm{C}$, and locally below $-3^{\circ} \mathrm{C}$, by MAR compared to the CRU datasets in our region of interest with a $10 \mathrm{~km}$ spatial resolution. The $5 \mathrm{~km}$ spatial resolution simulation (Fig. $4 \mathrm{~b}$ ) shows a lower underestimation of the mean temperature compared to the coarser $10 \mathrm{~km}$ resolution. Only a small portion of the eastern part shows temperature biases below $-2^{\circ} \mathrm{C}$.

\section{Precipitation biases}

Fig. 5a and $\mathrm{b}$ show a general overestimation of the annual precipitation by MAR compared to CRU. The total sum of precipitation simulated is overestimated up to +125 to $+250 \mathrm{~mm} / \mathrm{yr}$, locally above $250 \mathrm{~mm}$, per year compared to CRU in the eastern part with some local and slight underestimation of $-50 \mathrm{~mm} / \mathrm{yr}$. Unlike the temperature bias, no substantial difference between both 10 and $5 \mathrm{~km}$ simulations is observed. It is important to note that this underestimation is more pronounced in high altitude areas where CRU turns out to be less accurate, particularly in terms of precipitation (Solman et al., 2013).

Both underestimation of the mean temperature and overestimation of the precipitation lead us to conclude that MAR is not able to represent the Foehn events and, therefore, the rain shadow effect over Patagonia. After comparison between the two resolutions, we can observe that a finer spatial resolution in our model produces temperature output 
fields closer to the CRU datasets. However, the biases for the precipitation output fields are still present.

\subsection{Sensitivities experiments}

Three DEM generalization sensitivity experiments, including a change in the DEM generalization method, are developed to assess the impacts of the surface elevation generalization on MAR 2m-temperature and precipitation (rain + snow) outputs over the 2002-2016 period. It should be noted that we call "DEM generalization sensitivity experiments" the experiments that evaluate the sensitivity of MAR to the DEM generalization inputs. We perform three anomalies for each additional DEM method representing the difference between the results of each sensitivity experiments and the reference run. Unlike the validation of the MAR where the added value of a finer resolution was questioned, only the results at spatial resolution $10 \mathrm{~km}$ are discussed here to focus on the added value of a DEM generalization modified grid.

\section{Temperature anomaly}

In a large part of our region of interest (delimited by a black rectangle in Fig. 6), MAR using the P90 method (Fig. 6a) produces a slight increase in the mean temperature of around +0.25 to $+0.5^{\circ} \mathrm{C}$ and locally $+1^{\circ} \mathrm{C}$ compared to the reference run. However, only the areas with the largest increases between +0.5 and $+1^{\circ} \mathrm{C}$ are significant, i.e. the anomaly is higher than the interannual variability. With the EM method (Fig. 6b), temperature anomalies rise significantly from +0.5 to $+3^{\circ} \mathrm{C}$ across all the region compared to the reference run. The TC method results (Fig. 6c) show temperature anomalies reaching a northern significant increase of +0.5 to $+1^{\circ} \mathrm{C}$ and a southern slight and non-significant increase of +0.25 to $+0.5^{\circ} \mathrm{C}$ compared to the reference run. Outside the region of interest, temperature anomalies drop from -3 to $-4^{\circ} \mathrm{C}$ around the mountain range for the P90 and EM methods as the topography is substantially higher. Regarding the TC method, results are considerably different; the valleys exhibit an increase in temperature anomaly, whereas, only high local peaks show a decrease in temperature anomaly. Let us point out that the pixelized appearance is due to the fact that this 
method tries to reproduce more valleys and crests orographic features in the region.

\section{Precipitation anomaly}

MAR using the P90 method (Fig. 7a) induces a slight and non-significant decrease of annual precipitation from 0 to $-100 \mathrm{~mm} / \mathrm{yr}$ over the eastern plain area and a significant decrease between -100 to below $-150 \mathrm{~mm} / \mathrm{yr}$ over the northern mid-altitudes areas compared to the reference run. This decrease is similar but amplified with the EM method (Fig. 7b). The results of the latter are between -50 to below $-150 \mathrm{~mm} / \mathrm{yr}$ with local peaks reaching $-500 \mathrm{~mm} / \mathrm{yr}$. Meanwhile, precipitation anomaly of the TC method (Fig. 7c) does not present any significant increase or decrease in the plain area. Outside our region of interest, the results are again contrasting between an increase in precipitation for the P90 and EM methods and a decrease of precipitation for the TC method.

\section{Discussion and conclusion}

Current RCMs and GCMs have always struggled to model Foehn effects in Patagonia. Studies carried out in the region emphasize that an inaccurate orographic representation is responsible for these precipitation-related modeling deficiencies. In addition to previous studies using a finer spatial resolution to resolve this flaw, we work on the hypothesis that a more appropriate choice of DEM generalization method would better represent the mountain barrier and would, therefore, allow a more consistent air masses modeling in Patagonia. We evaluated the influence of three additional DEM generalization methods (P90, EM, and TC) to the standard mean box method on climatic variables in Patagonia, using a reference run and three DEM generalization sensitivity experiments performed by an orographic-derived version of MAR.

Our model validation shows an underestimation of annual mean temperatures and an overestimation of annual precipitation compared to $\mathrm{CRU}$ on the east of the mountains, our region of interest. This can be explained by the fact that the mean generalization method underestimates the altitude of the mountain range, a key component to represent the blocking effect. The warm and dry air masses, i.e. the rain shadow effect, on the lee side of the Andes mountains resulting from Foehn winds are, therefore, not well 
reproduced. Thanks to the $5 \mathrm{~km}$ simulation, we observe that a finer spatial resolution can considerably improve the temperature output fields of our model compared to CRU. However, it cannot resolve the biases observed in the precipitation output fields. These results are consistent with other studies carried out over this region (Solman et al., 2013; Garreaud et al., 2013; Garreaud et al., 2016).

On the other hand, the DEM generalization sensitivity experiments were supposed to give us an insight on the surface elevation generalization capability to better reproduce the mountain range and, as a consequence, the warm and dry air masses. Results considerably confirm this hypothesis with an increase in mean temperature in our region of interest for all three DEM generalization methods with high, medium and medium-low significance for the EM, TC and P90 method, respectively. For instance, the EM method simulates temperature anomalies $\left(+0.5\right.$ to $\left.+3^{\circ} \mathrm{C}\right)$ counter balancing the temperature biases $\left(-1\right.$ to $\left.-3^{\circ} \mathrm{C}\right)$ observed again $\mathrm{CRU}$. In terms of precipitation, only the EM and partly the P90 methods induce a significant decrease in precipitation in our region of interest, e.g. the EM method displays precipitation anomalies (-50 to below $-150 \mathrm{~mm} / \mathrm{yr}$ ) partially offsetting the precipitation biases $(+125$ to above $+250 \mathrm{~mm} / \mathrm{yr})$ observed against CRU. The results are more contrasted for the TC method where precipitation slightly decrease or increase depending on the areas. This could be related to the fact that our last method better represents the valleys at the expense of a perfect homogenization of the mountain range. The air masses can, therefore, cross this irregular range and produce more precipitation.

The results of our findings lead us to conclude that the EM, following by the P90, generalization methods allow a more consistent air masses modeling thanks to a better mountain range representation. As a matter of fact, the surface elevation computed by these methods blocks cold and wet winds coming from the ocean and reproduces the rain shadow effect.

In the end, we can draw the conclusion that our model is more consistent for representing the rain shadow effect in Patagonia when using a preferable choice of DEM generalization. This research can serve as a recommendation for better use of DEM generalization to existing climate models performing in Patagonia but also in all regions 
where Foehn events can be observed as well as in regions sharing the same orographic features as the Patagonian relief.

In light of our study, we suggest some perspectives on this topic. Firstly, our research was limited to the CRU gridded climate datasets to verify the standard performance of the model. Validation of the model could, therefore, be performed with other gridded climate datasets available in the region, but also with a meteorological station network analysis. Secondly, there is a deep need for better documentation and use of the different DEM generalization methods in climate models. The benefit and the value of this component are too often overlooked in climatology. More efficient use of these would lead to more consistent Foehn effects modeling and other climatic features, especially in complex orographic areas.

\section{Appendix S1: Description of the EM generalization method}

The aim of this method is to preserve the mountain range by retaining to a large extent the high altitudes at the expense of the low altitudes, e.g. the valleys. The prototype algorithm was implemented using the ArcGIS software. Nevertheless, a similar procedure can easily be implemented in any climate model.

Fig. 8 illustrates the six steps performed to obtain the final DEM. Firstly, we need to isolate summits or peaks in the study area. To achieve this, two steps are necessary: (b) the values of the pixels in the input DEM are replaced by the maximum altitude inside a circle with a specific radius equal to the user-defined output DEM resolution (in our case $10 \mathrm{~km}$ ). After that, (c) the difference between the input DEM and the local maximum found in (b) allows us to isolate the summits. These peaks are the nodes used in (d) the TIN construction. The latter is then (e) rasterised and finally (f) an extraction in this raster is done at each pixel of the output coarser resolution DEM. It should be noted that this procedure can be iterative and an extra step (c) can isolate a surplus of summits by deducting the TIN raster with the former input DEM. In this way, we can add the points above the TIN raster into the set of peaks and restart the TIN construction at step (c) with the improved peaks set. In our study, two iterative operations were performed. 


\section{Appendix S2: Description of the TC generalization method}

The two other methodologies (P90 and EM) are focused on enhancing high altitudes, i.e. reproducing the blocking effect. However, the representation of valleys and plains plays a primal role in climate modeling. This enables a more consistent picture of temperatures, precipitation, wind fields, and other climatic variables. The aim of the method is, therefore, to satisfy this need while maintaining as many peaks and mountain ridges as possible. This method, therefore, keeps both high spatial frequencies (low altitudes points with valleys and high altitudes point with crests), and thus enhances the high relief amplitude. Consequently, the slope between pixels will increase. Once again, we used ArcGIS to implement the prototype algorithms. Nevertheless, a similar procedure could be directly implemented in any climate models.

The initial idea of this method consists in identifying a series of watersheds and thalwegs (line of maximum area drained) in our study area using a series of hydrological processing tools of DEM.

Initially, as Wu et al. (2008) have noted, we consider the presence of sinks. A DEM sink occurs when all neighbouring cells are higher than the central cell, which has no down-slope flow path to a neighbour cell. Sinks could be the result of real components of the terrain, but also of input errors or interpolation artifacts. They lead to interrupt the flow accumulation computation. The sinks are, therefore, commonly removed prior to DEM processing for a more consistent thalweg and watershed identification. Then, we identify a series of thalwegs thanks to a reclassification of the flow accumulation raster with values superior to 50 pixels, value that we judged significant for a thalwegs identification. This reclassification combined to a classification of the thalweg (upstream or downstream confluence) and the flow direction computation allow us to identify a series of watersheds.

Fig. 9 shows a portion of the area with the resulting thalwegs and watersheds. Note that watershed borders partially correspond to crests.

Subsequently, the altitude of each pixel is calculated according to its proximity to the closest crest and the closest thalweg. Four variables per pixel are needed to calculate its altitude. Firstly, two cost values are attributed to all pixels on the input high-resolution 
DEM depending on their distance to (i) the closest thalweg and (ii) the closest crest. It should be noted that the cost distances are not calculated using a classical Euclidean method but using the flow direction. Fig. 10 and 11 show the thalweg and crest cost distance rasters respectively. In addition to the cost distances, we attribute to all pixels the altitude value of (iii) the closest crest and (iv) the closest thalweg. Then, the two cost distance rasters are needed to calculate if each pixel is closer to a crest or to a thalweg. In the first case, the altitude of the pixel will be the altitude of the crest, in the second case the altitude of the thalweg. Both are retrieved from the (iii) and (iv) rasters. Fig. 12 shows the altitude attribution of a subset of the study area depending on their proximity with crest or thalweg.

It should be noted that our method is empirical and can be improved in different ways. For example, a crucial step in this method is the identification of the thalwegs in our region. As explained earlier, this identification is performed by a reclassification of the flow accumulation raster. The threshold of this reclassification, fixed at 50 pixels in our study, was chosen subjectively and not quantitatively. Instead of selecting one value, we could retrieve several DEM from this method using several different thresholds. Taking another example, we could weight the pixels altitude with a weighted average of the distance between the pixel and the closest thalweg or crest.

\section{Appendix S3: Short analysis of the four generalization methods used}

In this section, we discuss the difference between the four DEMs obtained. A generalization is considered to be accurate if its result shows spatial altitude frequencies close to the former high-resolution DEM. We have deliberately chosen not to illustrate this DEM generalization comparison with maps because it would require an interpolation of the low-resolution DEM at the former high-resolution input DEM. As a consequence, the accuracy of the resulting interpolated DEM would depend on the interpolation used and not only on our former four generalizations.

We display relative cumulated frequency histograms of altitude values over the whole area of interest and for the four methods in figure 13. The closer the frequency curve of a method is to the curve of the original surface elevation the more consistent the method 
could be considered. The mean and TC methods are therefore the most consistent because their frequency curve is nearly similar to the one of our input DEM. Concerning the P90 and more the envelope method, they fail to reproduce the same distribution, especially between 500 to $1500 \mathrm{~m}$. It should be highlighted that in our case, we are mainly looking for a generalization method which can reproduce the blocking effect of the Andes, e.g. really high altitudes (see the maximum altitude represented by vertical lines in figure 13). From this point of view, the EM method seems to be the more adequate followed by the TC and P90 methods.

\section{References}

Amante, C. and Eakings, B. (2009) Etopo1 1 arc-minute global relief model: procedures, data sources and analysis. URL: http://www.ngdc.noaa.gov/mgg/global/global.html.

Andrew, O., Tony, P., Stuart, W., Andy, E., Mark, W., Scott, H. and John, T. (2014) Met office unified model high-resolution simulations of a strong wind event in antarctica. Quarterly Journal of the Royal Meteorological Society, 140, 2287-2297.

Barthélemy, A., Goosse, H., Mathiot, P. and Fichefet, T. (2012) Inclusion of a katabatic wind correction in a coarse-resolution global coupled climate model. Ocean Modelling, $48,45-54$.

Berman, A. L., Silvestri, G. and Compagnucci, R. (2012) Eastern patagonia seasonal precipitation: Influence of southern hemisphere circulation and links with subtropical south american precipitation. Journal of Climate, 25, 6781-6795.

Bianchi, E., Villalba, R., Viale, M., Couvreux, F. and Marticorena, R. (2016) New precipitation and temperature grids for northern patagonia: Advances in relation to global climate grids. Journal of Meteorological Research, 30, 38-52.

Bindlish, R. and Barros, A. P. (1996) Aggregation of digital terrain data using a modified fractal interpolation scheme. Computers \& Geosciences, 22, 907-917. 
De Ridder, K. and Gallée, H. (1998) Land surface-induced regional climate change in southern israel. Journal of Applied Meteorology, 37, 1470-1485.

Dee, D. P., Uppala, S. M., Simmons, A., Berrisford, P., Poli, P., Kobayashi, S., Andrae, U., Balmaseda, M., Balsamo, G., Bauer, d. P. et al. (2011) The era-interim reanalysis: Configuration and performance of the data assimilation system. Quarterly Journal of the royal meteorological society, $\mathbf{1 3 7}, 553-597$.

$\begin{array}{cccccc}\text { ECMWF } & (2003) & \text { Ifs } & \text { documentation, part iv: Physical pro- } \\ \text { cesses } & (\text { cy25r1). } & \text { The Library ECMWF, Reading. } & \text { URL: }\end{array}$

https://www.ecmwf .int/sites/default/files/elibrary/2007/9221-part-iv-physical-processes.pdf.

Elvidge, A. D. and Renfrew, I. A. (2016) The causes of foehn warming in the lee of mountains. Bulletin of the American Meteorological Society, 97, 455-466.

Fettweis, X., Box, J., Agosta, C., Amory, C., Kittel, C., Lang, C., van As, D., Machguth, H. and Gallée, H. (2017) Reconstructions of the 1900-2015 greenland ice sheet surface mass balance using the regional climate mar model. Cryosphere (The), 11, 1015-1033.

Fettweis, X., Gallée, H., Lefebre, F. and Van Ypersele, J.-P. (2005) Greenland surface mass balance simulated by a regional climate model and comparison with satellitederived data in 1990-1991. Climate Dynamics, 24, 623-640.

Gallée, H. and Schayes, G. (1994) Development of a three-dimensional meso- $\gamma$ primitive equation model: katabatic winds simulation in the area of terra nova bay, antarctica. Monthly Weather Review, 122, 671-685.

Gallée, H., Fontaine de Ghélin, O. and van den Broeke, M. R. (1995) Simulation of atmospheric circulation during the gimex 91 experiment using a meso- $\gamma$ primitive equations model. Journal of Climate, 8, 2843-2859.

Gallée, H. and Pettré, P. (1998) Dynamical constraints on katabatic wind cessation in adélie land, antarctica. Journal of the Atmospheric Sciences, 55, 1755-1770.

Garreaud, R., Falvey, M. and Montecinos, A. (2016) Orographic precipitation in coastal southern chile: Mean distribution, temporal variability, and linear contribution. Journal of Hydrometeorology, 17, 1185-1202. 
Garreaud, R., Lopez, P., Minvielle, M. and Rojas, M. (2013) Large-scale control on the patagonian climate. Journal of Climate, 26, 215-230.

George, T., Costas, D. and Christos, Z. (2012) Does dynamical downscaling introduce novel information in climate model simulations of precipitation change over a complex topography region? International Journal of Climatology, 32, 1572-1578.

Harris, I., Jones, P., Osborn, T. and Lister, D. (2014) Updated high-resolution grids of monthly climatic observations-the cru ts3. 10 dataset. International Journal of Climatology, 34, 623-642.

Hong, S.-Y. (1999) New global orography data sets. Office note 424.

Jacques-Coper, M., Brönnimann, S., Martius, O., Vera, C. S. and Cerne, S. B. (2015) Evidence for a modulation of the intraseasonal summer temperature in eastern patagonia by the madden-julian oscillation. Journal of Geophysical Research: Atmospheres, 120, 7340-7357.

Kittel, C., Amory, C., Agosta, C., Delhasse, A., Doutreloup, S., Huot, P.-V., Wyard, C., Fichefet, T. and Fettweis, X. (2018) Sensitivity of the current antarctic surface mass balance to sea surface conditions using mar. Cryosphere (The), 12, 3827-3839.

Klink, K. (1995) Surface aggregation and subgrid-scale climate. International journal of climatology, 15, 1219-1240.

Le Coz, M., Delclaux, F., Genthon, P. and Favreau, G. (2009) Assessment of digital elevation model (dem) aggregation methods for hydrological modeling: Lake chad basin, africa. Computers $\&$ Geosciences, 35, 1661-1670.

Lenaerts, J. T. M., van den Broeke, M. R., van Wessem, J. M., van de Berg, W. J., van Meijgaard, E., van Ulft, L. H. and Schaefer, M. (2014) Extreme precipitation and climate gradients in patagonia revealed by high-resolution regional atmospheric climate modeling. Journal of Climate, 27, 4607-4621.

Lenderink, G. and Lenderink, G. (2003) Simulation of present-day climate in RACMO2: first results and model developments. Koninklijk Nederlands Meteorologisch Instituut. URL: http://bibliotheek.knmi.nl/knmipubTR/TR252.pdf. 
Mathiot, P., Barnier, B., Gallée, H., Molines, J. M., Le Sommer, J., Juza, M. and Penduff, T. (2010) Introducing katabatic winds in global era40 fields to simulate their impacts on the southern ocean and sea-ice. Ocean Modelling, 35, 146-160.

Mazzoni, E. and Vazquez, M. (2009) Desertification in patagonia. Developments in Earth Surface Processes, 13, 351-377.

Paruelo, J. M., Beltrán, A., Jobbagy, E., Sala, O. E. and Golluscio, R. A. (1998) The climate of patagonia: general patterns and controls on biotic processes. Ecología Austral, 8, 85-101.

Seluchi, M. E., Norte, F. A., Satyamurty, P. and Chou, S. C. (2003) Analysis of three situations of the foehn effect over the andes (zonda wind) using the eta-cptec regional model. Weather and forecasting, 18, 481-501.

Smith, R. B. and Evans, J. P. (2007) Orographic precipitation and water vapor fractionation over the southern andes. Journal of Hydrometeorology, 8, 3-19.

Solman, S. A., Sanchez, E., Samuelsson, P., da Rocha, R. P., Li, L., Marengo, J., Pessacg, N. L., Remedio, A., Chou, S., Berbery, H. et al. (2013) Evaluation of an ensemble of regional climate model simulations over south america driven by the era-interim reanalysis: model performance and uncertainties. Climate Dynamics, 41, 1139-1157.

Viale, M. and Garreaud, R. (2015) Orographic effects of the subtropical and extratropical andes on upwind precipitating clouds. Journal of Geophysical Research: Atmospheres, 120, 4962-4974.

Vieux, B. E. (1993) Dem aggregation and smoothing effects on surface runoff modeling. Journal of Computing in Civil Engineering, 7, 310-338.

Wang, Y., Sen, O. L. and Wang, B. (2003) A highly resolved regional climate model (iprc-regcm) and its simulation of the 1998 severe precipitation event over china. part i: Model description and verification of simulation. Journal of Climate, 16, 1721-1738.

Wehner, M. F., Smith, R. L., Bala, G. and Duffy, P. (2010) The effect of horizontal resolution on simulation of very extreme us precipitation events in a global atmosphere model. Climate dynamics, 34, 241-247. 
Wu, S., Li, J. and Huang, G. (2008) A study on dem-derived primary topographic attributes for hydrologic applications: Sensitivity to elevation data resolution. Applied Geography, 28, 210-223. 


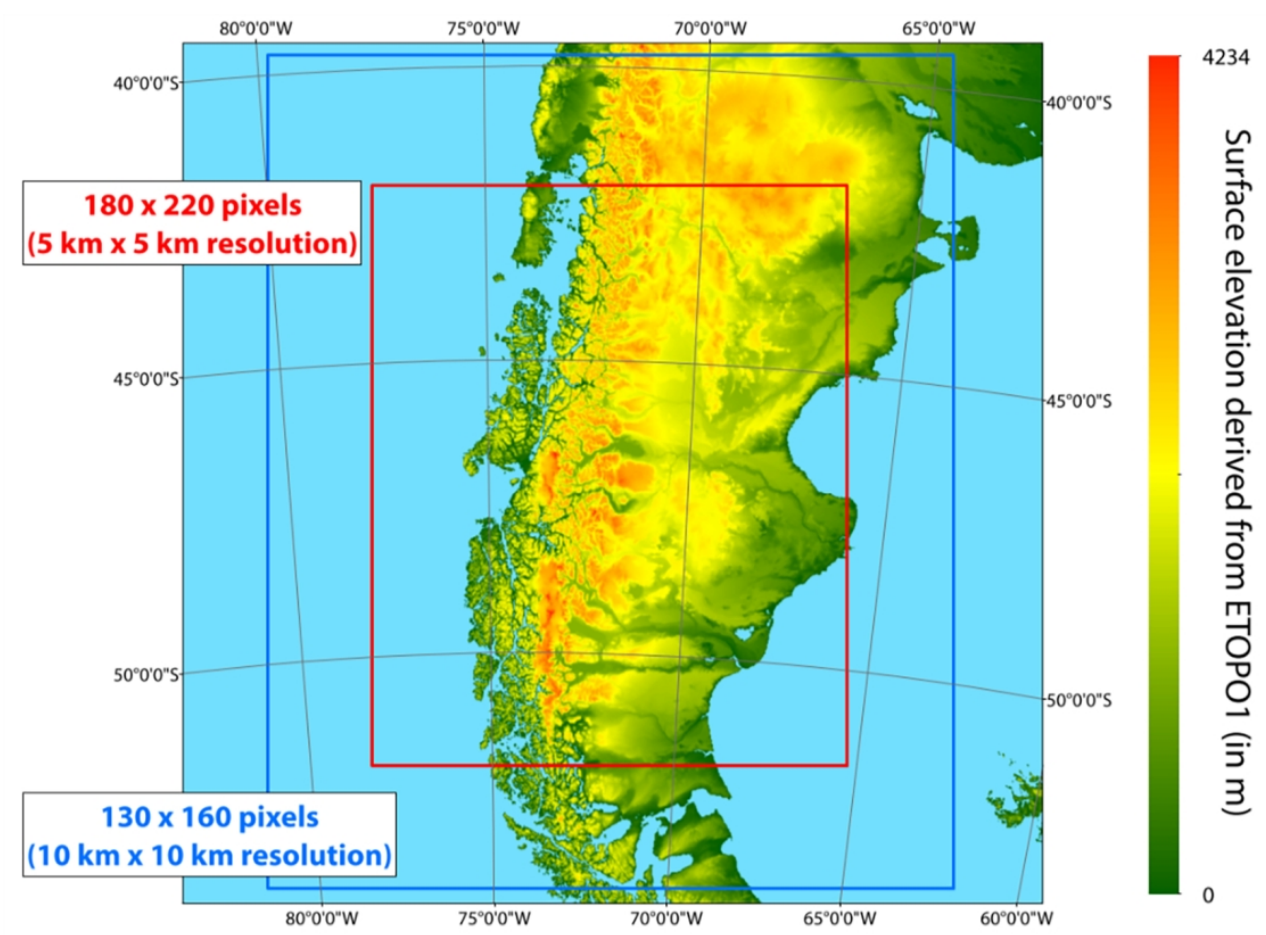

Fig. 1. The two domains used in our study. The blue rectangle represents the $10 \mathrm{~km}$ coarser spatial resolution. It includes $130 \times 160$ pixels. The red rectangle represents the domain with the $5 \mathrm{~km}$ finer spatial resolution. It includes $180 \times 220$ pixels. The common coordinate projection used is an azimuthal Postel oblique with a central meridian at $74 \mathrm{~W}$ and a latitude of origin at $47^{\circ} \mathrm{S}$. The palette represents the surface elevation of ETOPO1 (1 arc-minute resolution), the input DEM used in our study (see Amante and Eakings (2009) for the complete documentation about ETOPO1). 


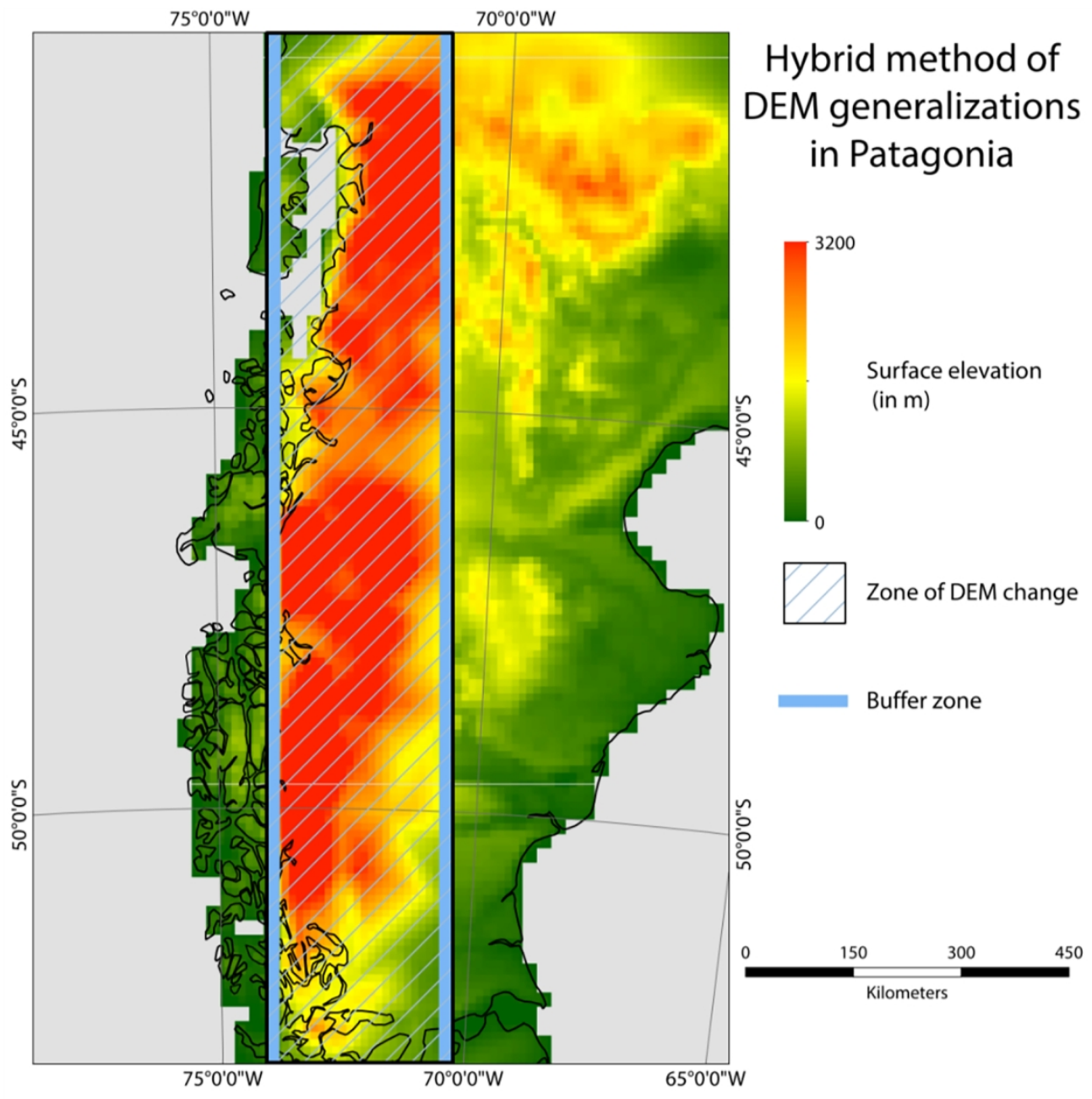

Fig. 3. Scheme of the hybrid method used to represent two different DEM generalization strategies in Patagonia. The palette represents the surface elevation derived from both DEM generalization. Outside the rectangle, the mean method is displayed. The hatched rectangle represents the area where another DEM generalization method is applied, here the EM method. The vertical blue lines represent the 2-pixel buffer zone. 
(a) $10 \mathrm{~km}$
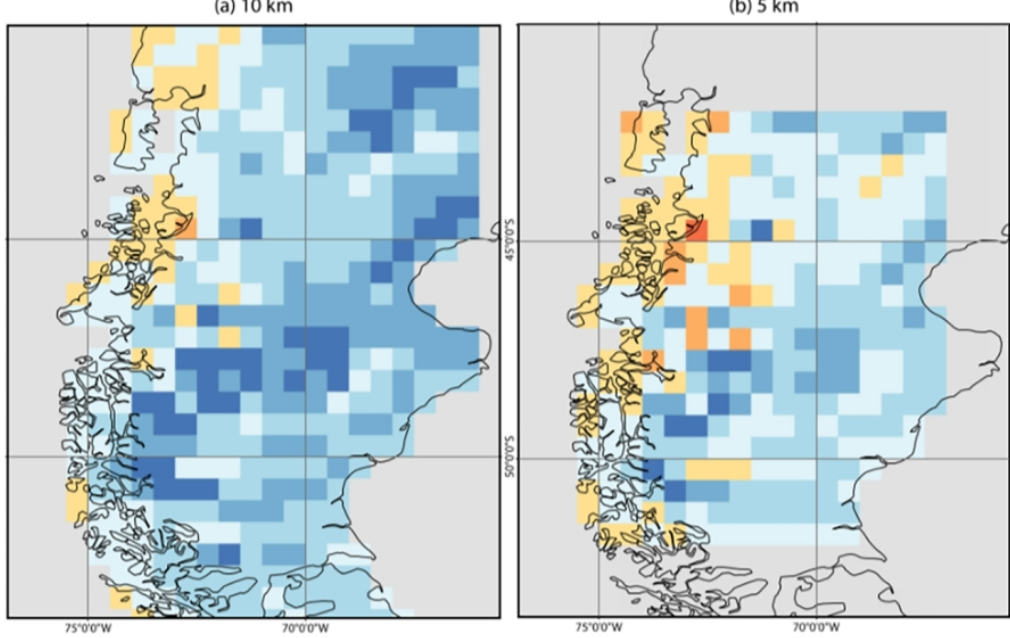

nnual mean temperature bias (in ${ }^{\circ} \mathrm{C}$ )

$[+3,+\infty[$

$[+2,+3[$

$\square[+1,+2[$

$\square[0,+1[$

$\square[-1,0[$

$\square[-2,-1]$

$\square[-3,-2[$

] $-\infty,-3[$

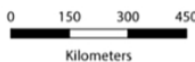

Fig. 4. Biases of the annual mean $2 m$-temperature (in ${ }^{\circ} \mathrm{C}$ ) using the MAR model over 20022016 compared to $\mathrm{CRU}$ in Patagonia with (i) a $10 \mathrm{~km}$ resolution and (ii) a $5 \mathrm{~km}$ resolution, both interpolated on the $0.5^{\circ} \times 0.5^{\circ} \mathrm{CRU}$ grid. Positive (negative) values mean an overestimation (underestimation) of MAR temperature with respect to CRU. 

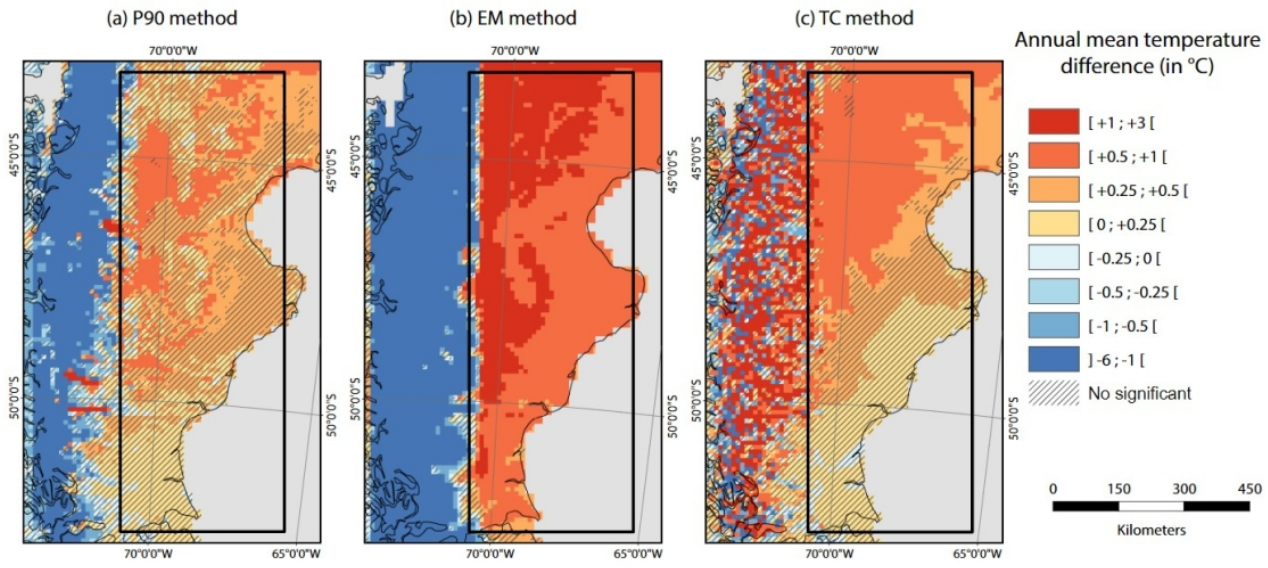

Fig. 6. Anomaly of the annual mean $2 \mathrm{~m}$-temperature in ${ }^{\circ} \mathrm{C}$ using (i) the percentile 90 method, (ii) the envelope maximum method or (iii) the thalwegs and crests method with respect to the reference run. The black rectangle is the region of our interest. The hatched zones represent the results where there is no significance (anomaly is superior to the interannual variability). Positive (negative) values mean an increase (decrease) in the mean $2 \mathrm{~m}$-temperature with respect to the former DEM mean method. 

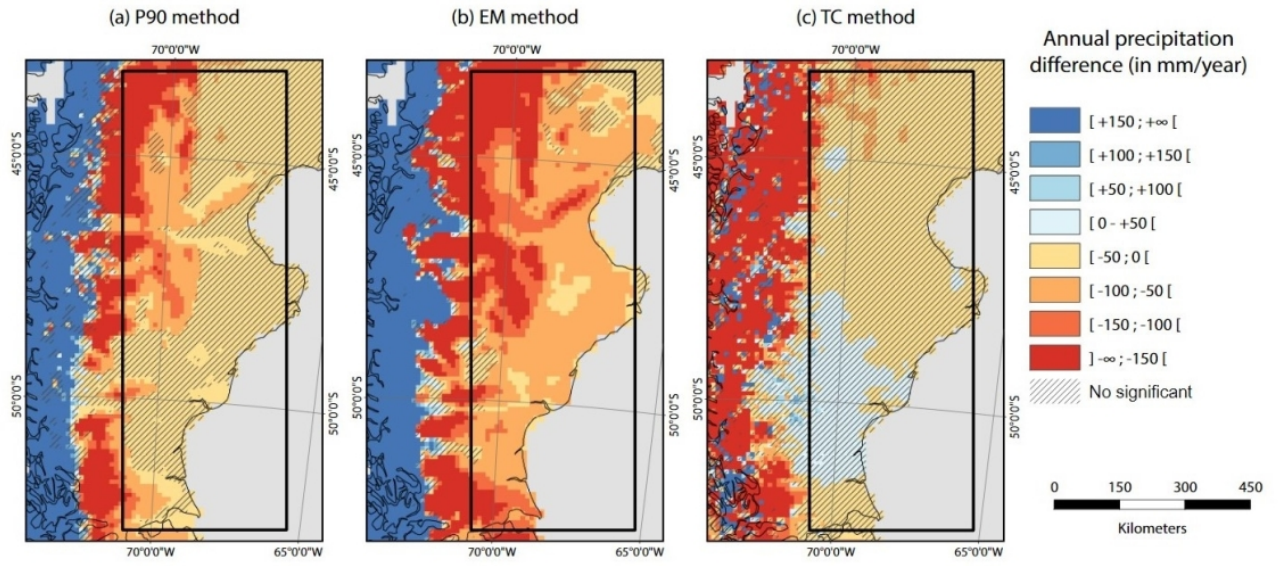

Fig. 7. Anomaly of the annual precipitation difference in $\mathrm{mm} / \mathrm{year}$ using (i) the percentile 90 method, (ii) the envelope maximum method or (iii) the thalwegs and crests method with respect to the reference run. The black rectangle is the region of our interest. The hatched zones represent the results where there is no significance (anomaly is superior to the interannual variability). Positive (negative) values mean an increase (decrease) in the annual precipitation sum with respect to the former DEM mean method. 


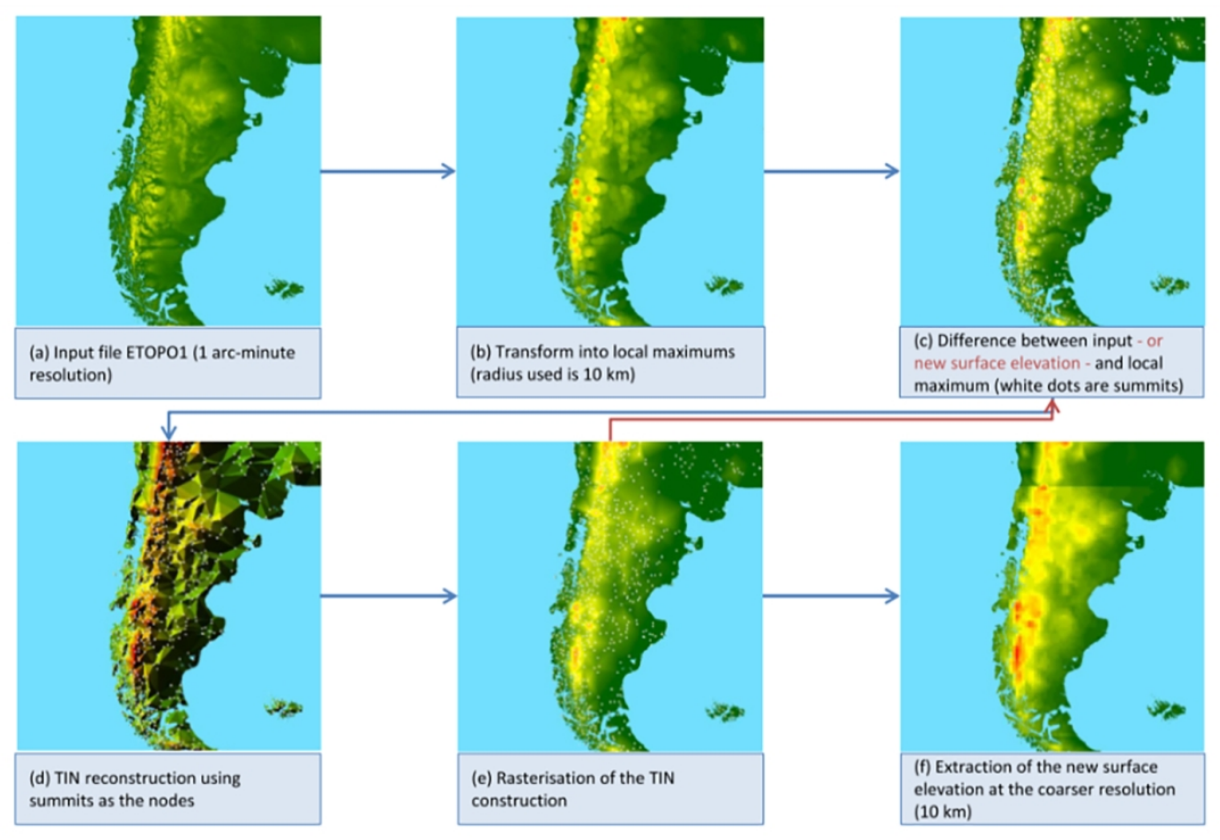

Fig. 8. Representation of the six steps performed in ArcGIS within the EM method. 


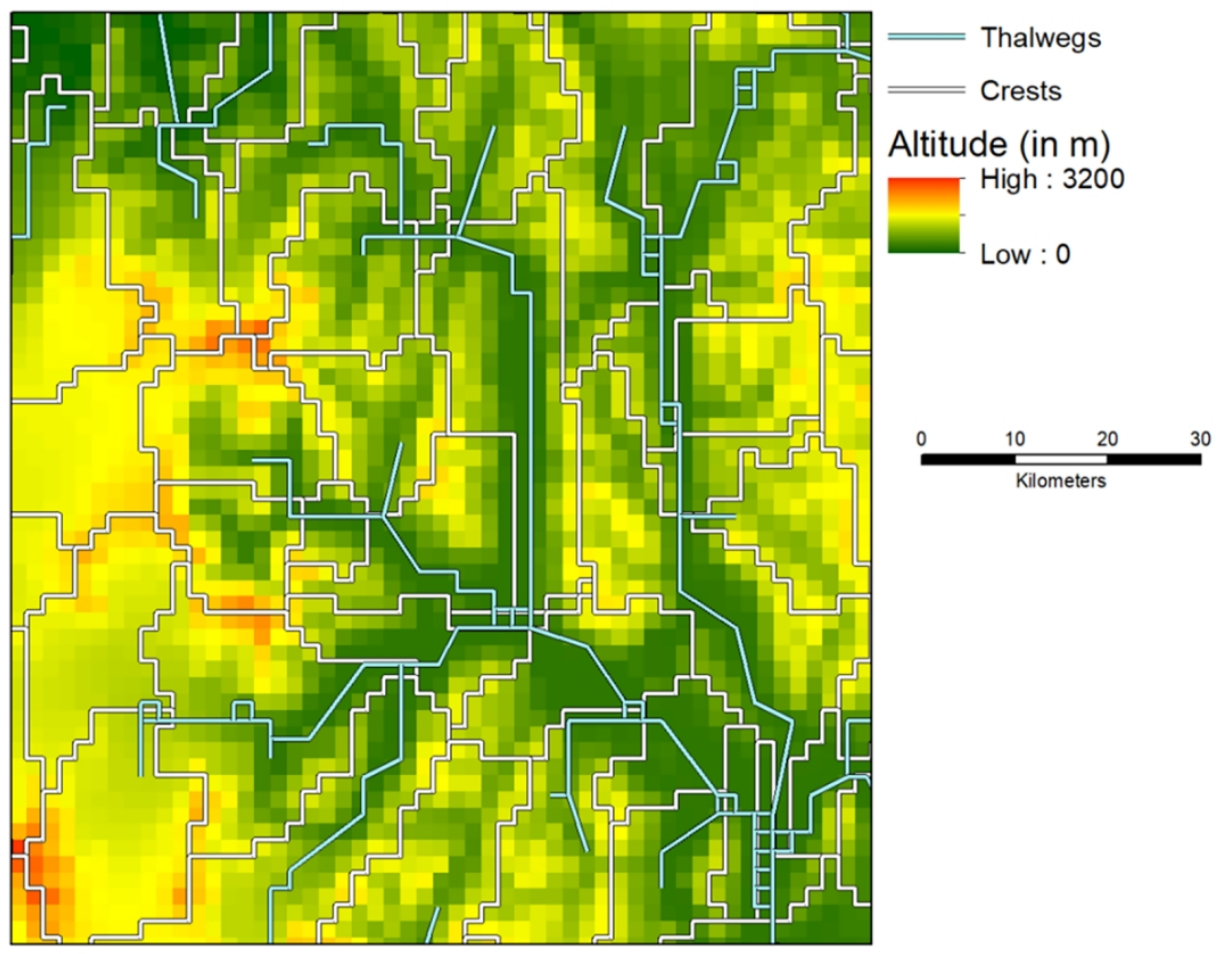

Fig. 9. Sample region of our domain showing thalwegs and crests retrieved using ArcGIS within the TC method. 


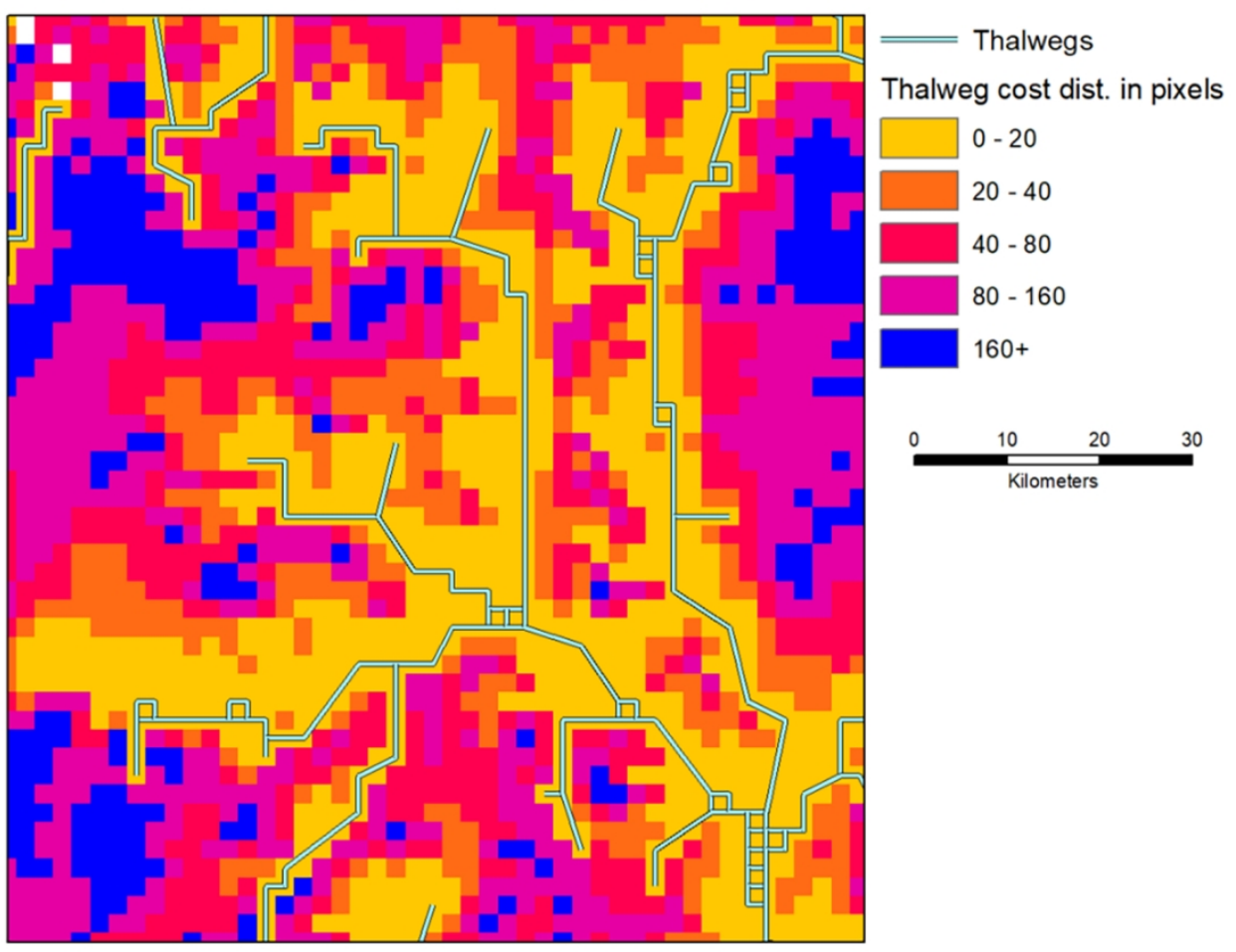

Fig. 10. Sample region of our domain showing the output result of the cost distance analysis computed by ArcGIS to the closest crest (represented by blue lines) within the TC method. 


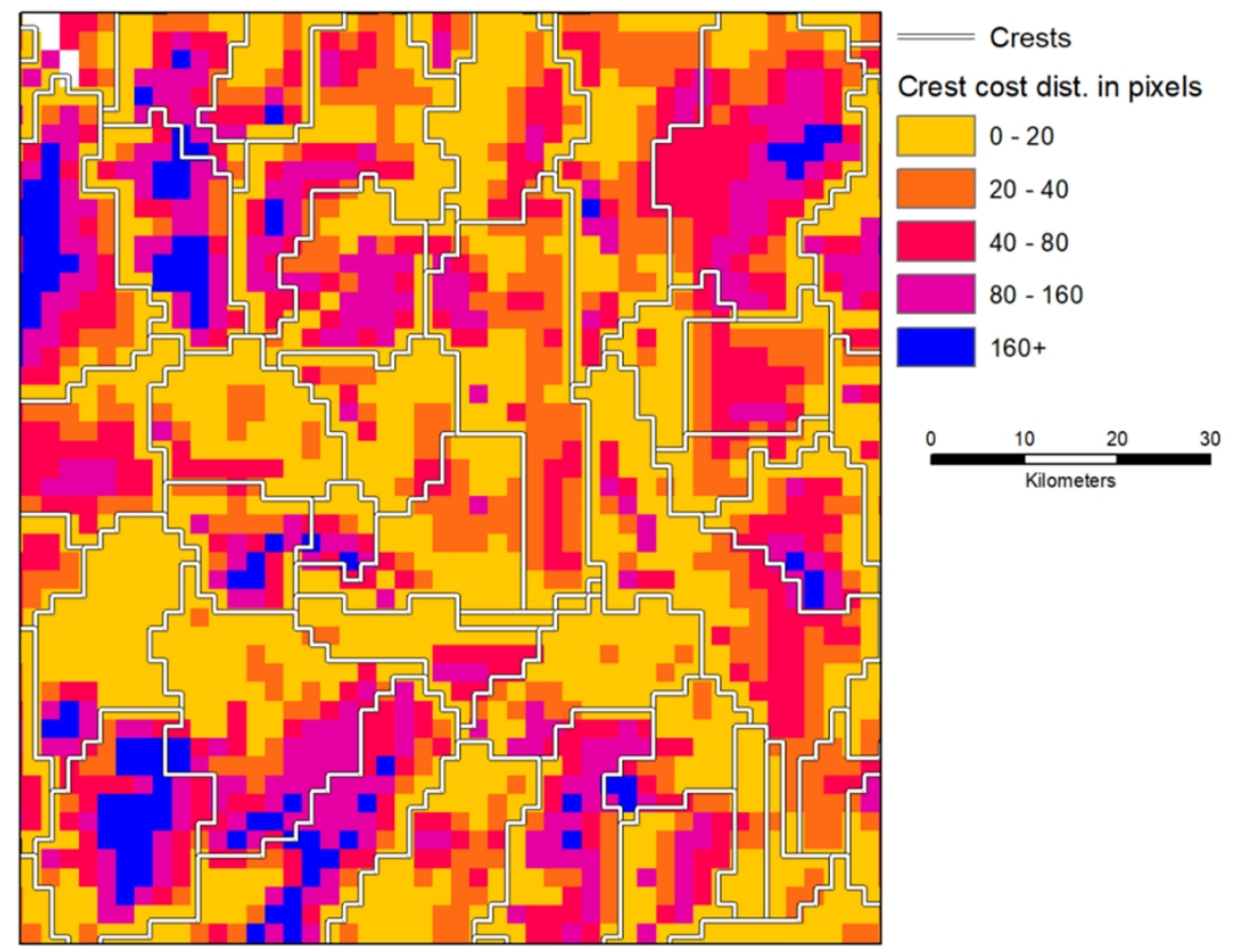

Fig. 11. Sample region of our domain showing the output result of the cost distance analysis computed by ArcGIS to the closest crest (represented by white lines) within the TC method. 


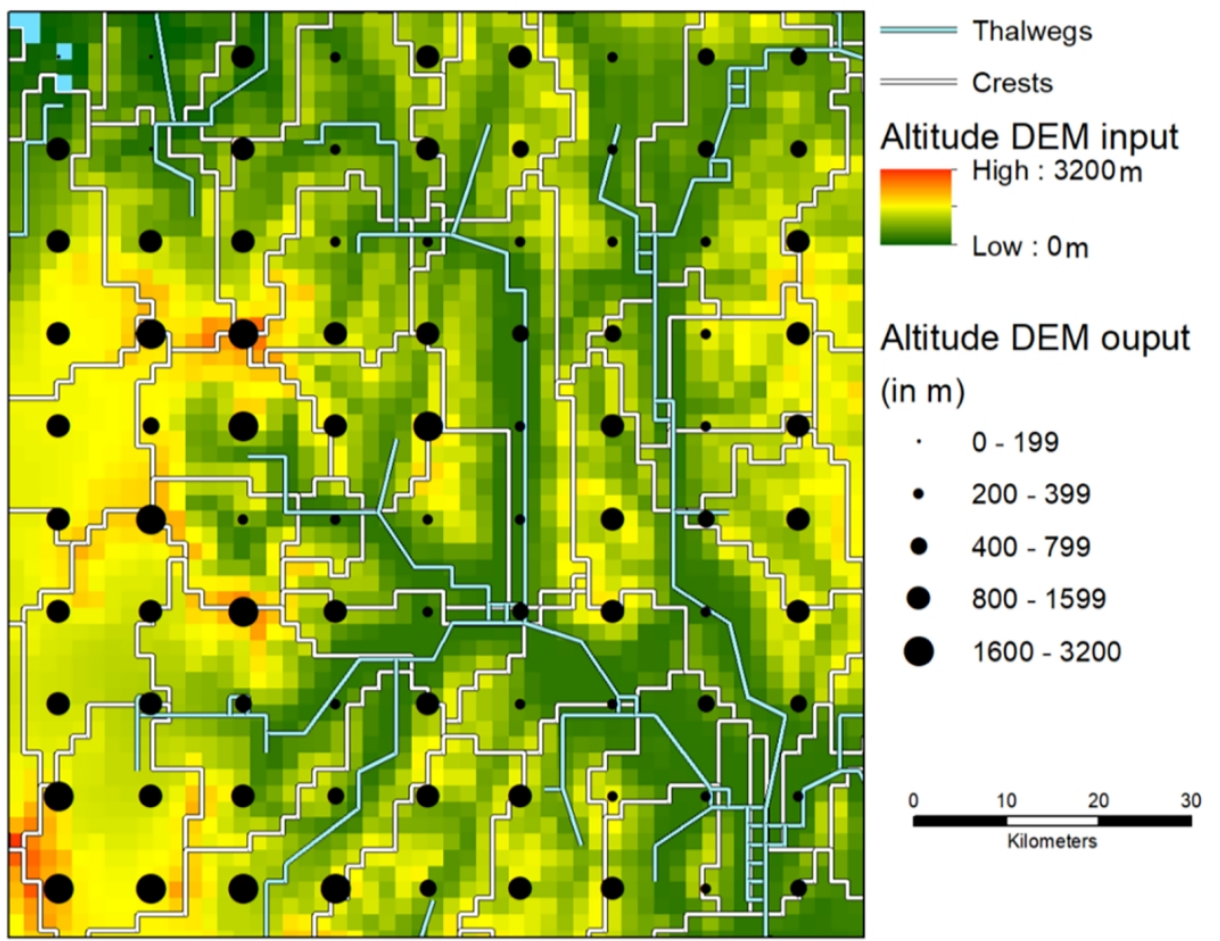

Fig. 12. Sample region in our domain showing altitude attribution of the low-resolution grid from the high-resolution grid (ETOPO1) using the thalwegs and crests method within the TC method. The pixels altitude of the low-resolution grid (represented by the black dots) are retrieved from a friction cost analysis between each dot and the DEM input altitude of the closest thalweg or crest (represented by, respectively, the blue and white lines). 


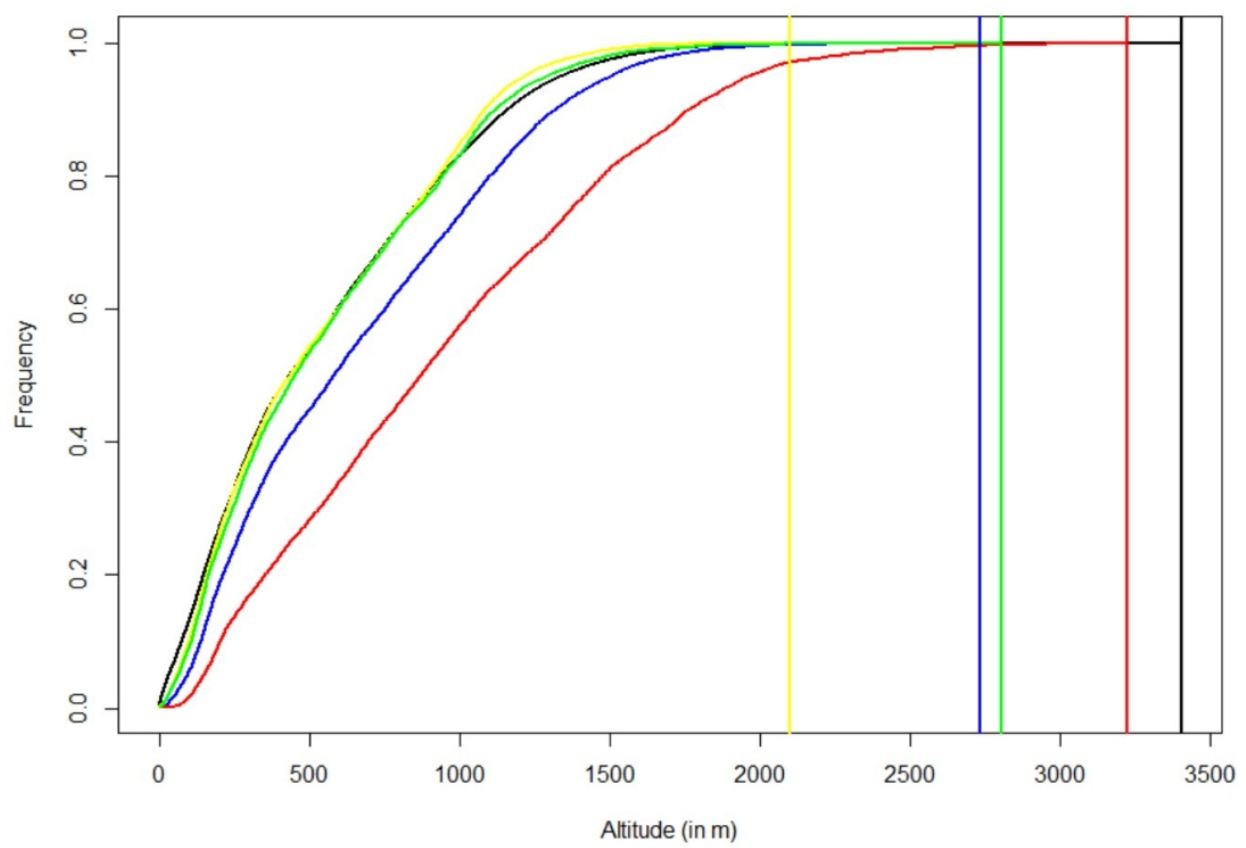

Fig. 13. Cumulative frequencies histogram of altitude with the four DEM generalization methods. The black curve represents the histogram of the original input DEM ETOPO1, the yellow one represents the mean method, the blue one represents the percentile 90 method, the red one represents the envelope maximum method and the green one represents the thalwegs and crests methods. The vertical lines represent the altitude of the uppermost pixel. The closer the curve of a method is to the curve of the original surface elevation the more consistent the method could be considered. 